UCRL-JC-121214

PREPRINT

\title{
Modeling Added Compressibility of Porosity and the Thermomechanical Response of Wet Porous Rock
}

\author{
M. B. Rubin \\ D. Elata \\ A. V. Attia \\ This paper was prepared for presentation at \\ 1995 APS Topical Conference on Shock Compression of Condensed Matter \\ August 13-18, 1995, Seattle, WA
}

June 1995

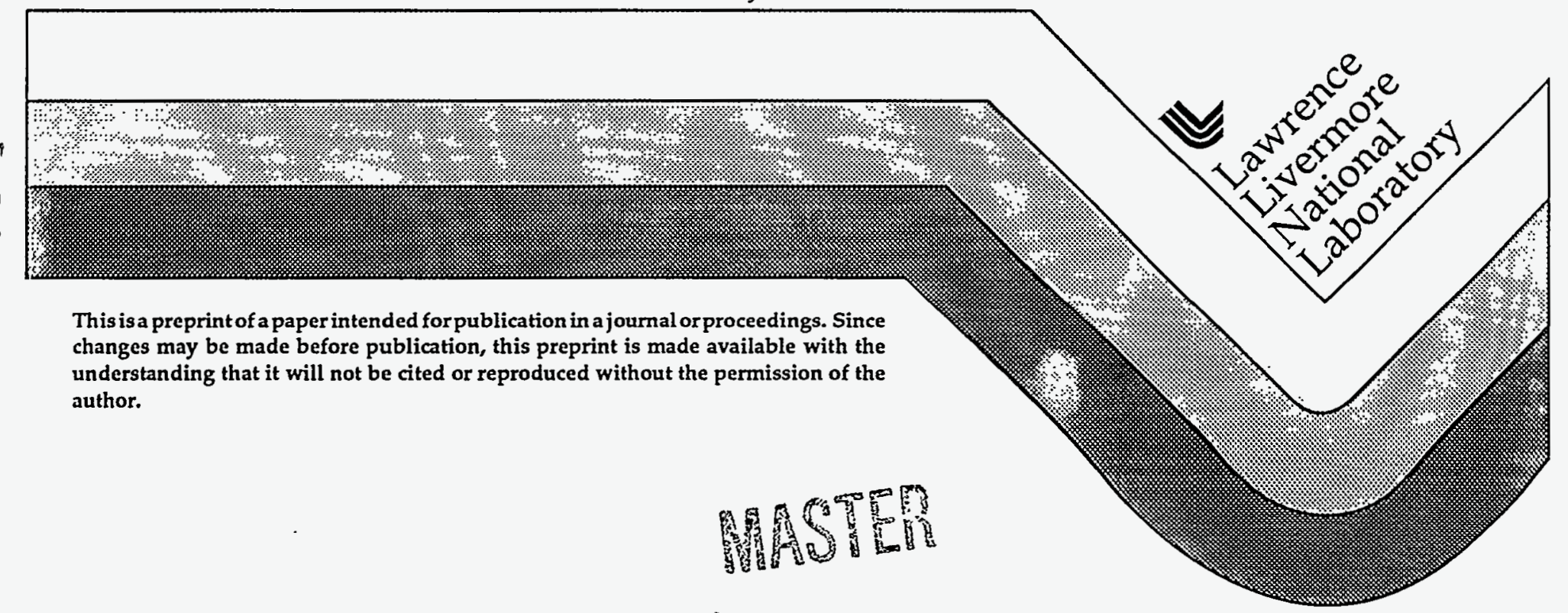

DETHIBUTION OF THIS DOCUMEAT IS UNLIMITED 


\section{DISCLAIMER}

Portions of this document may be illegible in electronic image products. Images are produced from the best available original document. 


\title{
MODELING ADDED COMPRESSIBILITY OF POROSITY AND THE THERMOMECHANICAL RESPONSE OF WET POROUS ROCK
}

\author{
M. B. Rubin*, D. Elata and A. V. Attia \\ Lawrence Livermore National Laboratory, Livernore, California, 94451 \\ "Pennanent address: Faculty of Mechanical Engineering, Technion, Haifa, 32000, Israel
}

\begin{abstract}
This paper is concerned with modeling the response of a porous brittle solid whose pores may be dry or partially filled with fluid. A form for the Helmholtz free energy is proposed which incorporates known MieGrüneisen constitutive equations for the nonporous solid and for the fluid, and which uses an Einstein formulation with variable specific heat. In addition, a functional form for porosity is postulated which depends on two material constants that control the added elastic compressibility of porosity observed in porous rock. Restrictions on constitutive assumptions for the composite of porous solid and fluid are obtained which ensure thermodynamic consistency. Examples show that although the added compressibility of porosity is determined by fitting data for dry Mt. Helen Tuff. the predicted responses of saturated and partially saturated tuff agree well with experimental data.
\end{abstract}

\section{INTRODUCTION}

This paper describes a thermomechanical constitutive model for the response of a rock-like material which is considered to be a composite of a multiply connected solid matrix whose pores are partially or fully saturated with water. The main objective of any theory for such porous materials is to use separate constitutive equations for the nonporous solid material and the fluid to obtain at constitutive equation for the response of the composite of the two materials. Specific constitutive equations have been developed ${ }^{l}$ which model the full range of response from low pressure at room temperature to high pressure at high temperature. Moreover, those constitutive equations use an Einstein formulation of the Helmholtz free energy with variable specitic heat. Although the theory in Ref. 1 includes the effects of plasticity on deviatoric stress here attention will be confined to a discussion of the constitutive equation for pressure.

Constitutive equations for $\mathrm{dry}^{2-4}$ and wet ${ }^{5}$ ductile porous materials have been developed in which a form is proposed for relating the total pressure $p$ in the composite of porous solid and tluid to the average pressure $\mathrm{p}_{\mathrm{s}}^{*}$ in the solid and the fluid pressure $\mathrm{p}_{\mathrm{f}}$ in the pores by the formula

$$
\mathrm{p}=(1-\phi) \mathrm{p}_{\mathrm{s}}^{*}+\phi \mathrm{p}_{\mathrm{f}},
$$

where $\phi$ is the porosity in the present configuration. However. the formula (1) does not provide a constitutive equation for the average solid pressure $\mathrm{p}_{\mathrm{s}}^{*}$ or for the porosity $\phi$.

Assuming that the solid and fluid have the same temperature $\theta$ it is common to take

$$
\begin{aligned}
& \mathrm{p}_{\mathrm{s}}^{*}=\hat{\mathrm{p}}_{\mathrm{s}}\left(\mathrm{J}_{\mathrm{s}}, \theta\right) . \\
& \mathrm{p}_{\mathrm{f}}=\hat{\mathrm{p}}_{\mathrm{f}}\left(\mathrm{J}_{\mathrm{f}}, \theta\right) .
\end{aligned}
$$

where the relative volumes of the solid $\mathrm{J}_{\mathrm{s}}$ and the tluid $\mathrm{J}_{\mathrm{f}}$ are given by

$$
\mathrm{J}_{\mathrm{s}}=\left(\frac{1-\phi}{1-\Phi}\right) \mathrm{J}, \mathrm{I}_{\mathrm{f}}=\frac{\phi}{S \Phi} \mathrm{J} .
$$

with $J$ being the total relative volume of the composite. $\Phi$ being the reference value of $\phi$ and $S$ being the reference value of saturation of tluid in the pores.

The assumption (2a) ignores the effect of stress concentrations near pores in the solid matrix and seems to predict an elastic response that is too stiff. To remedy this problem, the present work models the added elastic compressibility observed in the porous inaterial by proposing a function for the porosity 0 of the form 


$$
\phi=\hat{\phi}\left(\mathrm{J}, \theta, \phi_{\mathrm{u}}\right) \text {. }
$$

where $\phi_{\mathrm{u}}$ is a history dependent parameter characterizing the porosity of the solid matrix at zero stress and reference temperature $\theta_{0}$.

Prediction of the fluid pressure in the porous media is important because the deviatoric stress $\mathrm{T}$ ' is usually limited by distortional plasticity with the yield strength of the porous material being a function of both the pressure $\mathrm{p}$ and the fluid pressure $\mathrm{p}_{\mathrm{f}}$. In particular, the simplest assumptions of Terzaghi ${ }^{(3)}$ take the yield strength to be a function of the effective pressure $p_{e}$ which is defined by

$$
p_{\mathrm{e}}=\mathrm{p}-\mathrm{p}_{\mathrm{f}} \text {. }
$$

\section{THE THEORETICAL MODEL}

A simplified version of the theoretical model described in Ref. 1 takes the specific (per unit mass) Helmholtz free energy $\Psi_{s}$ and the pressure $P_{s}$ associated with the solid in the forms

$$
\begin{aligned}
& \Psi_{s}=\hat{\psi}_{s}\left(J_{s}, \theta\right) . \\
& p_{s}=\hat{p}_{s}\left(J_{s}, \theta\right)=-\rho_{s 0} \frac{\partial \Psi_{s}}{\partial J_{s}} .
\end{aligned}
$$

where $\rho_{\mathrm{s} 0}$ is the reference density of the solid. Also. the specific Helmholtz free energy $\psi_{\mathrm{f}}$ and the pressure $\mathrm{p}_{\mathrm{f}}$ associated with the fluid are taken in the forms

$$
\begin{aligned}
& \Psi_{\mathrm{f}}=\hat{\Psi}_{\mathrm{f}}\left(\mathrm{J}_{\mathrm{f}}, \theta\right) . \\
& \mathrm{p}_{\mathrm{f}}=\hat{\mathrm{p}}_{\mathrm{f}}\left(\mathrm{J}_{\mathrm{f}}, \theta\right)=-\rho_{\mathrm{f} 0} \frac{\partial \Psi_{\mathrm{f}}}{\partial \mathrm{J}_{\mathrm{f}}} .
\end{aligned}
$$

where $\rho_{f 0}$ is the reference density of the solid.

Next, the specitic Helmholtz free energy $\psi$ of the composite of solid and fluid is taken to be a mass weighted average of the Helmholtz free energies of the constituents such that

$$
\rho_{0} \Psi=(1-\Phi) \rho_{\mathrm{s} 0} \Psi_{\mathrm{s}}+S \Phi \Psi_{\mathrm{f}}
$$

where $\rho_{0}$ is the reference density of the composite. Using the thermodynamic procedures of Green and Naghdi ${ }^{7-8}$ it can be shown that for compressed states the total pressure $p$ and the specific internal energy $\varepsilon$ in the composite are given by

$$
\begin{aligned}
& p=-\rho_{0} \frac{\partial \psi}{\partial J}=(1-\phi) p_{\mathrm{s}}+\phi p_{\mathrm{f}}-\mathrm{J}\left(\mathrm{p}_{\mathrm{s}}-\mathrm{p}_{\mathrm{f}}\right) \frac{\partial \hat{\phi}}{\partial \mathrm{J}}, \\
& \rho_{0} \varepsilon=(1-\Phi) \rho_{\mathrm{s} 0} \varepsilon_{\mathrm{s}}+S \Phi \rho_{\mathrm{f} 0} \varepsilon_{\mathrm{f}},
\end{aligned}
$$

where $\varepsilon_{\mathrm{s}}$ and $\varepsilon_{\mathrm{f}}$ are the internal energies of the solid and fluid, respectively. Also, the rate of dissipation due to changes in the unloaded porosity $\phi_{u}$ is given by

$$
\rho \theta \xi_{\phi}^{\prime}=-\left(p_{\mathrm{s}}-p_{\mathrm{f}}\right) \frac{\partial \hat{\phi}}{\partial \phi_{\mathrm{u}}} \dot{\phi}_{\mathrm{u}} \geq 0,
$$

which is required to be nonnegative by the second law of thermodynamics.

For compressed states the function (4) is taken in the form

$$
\begin{aligned}
& \hat{\phi}=\phi_{\mathrm{u}}\left[1-\frac{\mathrm{a}}{\mathrm{b}} \tanh \gamma\right], \\
& \gamma=\frac{\mathrm{b}}{\Phi_{\mathrm{u}}}\left(1-\phi_{\mathrm{u}}\right)(\beta-1), \\
& \beta=\left(\frac{1-\Phi}{1-\phi_{\mathrm{u}}}\right) \frac{1}{\mathrm{~J}}, \quad 0 \leq \frac{\mathrm{a}}{\mathrm{b}}<1 .
\end{aligned}
$$

where the two constants a and $b$ control the added compressibility observed in porous materials and the condition (11d) ensures that $\hat{\phi}$ and $\phi_{u}$ have the same signs.

It can also be shown that when $a<1$ the restriction (10) prevents porous dilatation $\left(\dot{\phi}_{\mathrm{u}}>0\right)$ when the effective pressure $p_{e}$ is positive and it prevents porous compaction $\left(\dot{\phi}_{\mathrm{u}}<0\right)$ when $\mathrm{p}_{\mathrm{e}}$ is negative.

To complete the above theory it is necessary to provicle an evolution equation for determining $\phi_{u}$ of the form

$$
\dot{o}_{u}=\Gamma_{\phi},
$$

where $\Gamma_{\phi}$ is determined by satisfying consistency conditions associated with either a compaction surface $g_{\mathrm{c}}$ of the form

$$
g_{\mathrm{c}}=\mathrm{p}_{\mathrm{e}}-\mathrm{f}(\phi) \leq 0, \mathrm{f}(\phi) \geq 0 .
$$


or a dilation surface of the form

$$
\mathrm{g}_{\mathrm{d}}=-\mathrm{p}_{\mathrm{e}}-\kappa_{\mathrm{d}} \leq 0, \quad \kappa_{\mathrm{d}}>0 .
$$

Here, $f(\phi)$ is a nonnegative function determined by dry compaction data, $\kappa_{d}$ is a positive constant, and it is tacitly assumed that $p_{e}$ is a decreasing function of $\phi_{u}$ so that the conditions (13) and (14) will be compatible with the restriction (10).

\section{SOLUTION PROCEDURE}

The complete thermomechanical model (described in Ref. 1) has been implemented into the computer code DYNA2D. In the simplified model described here, the solution procedure is as follows. Given the value of all state variables at the beginning of a time step $t_{n}$ the values of $J$ and an estimate of $\varepsilon$ are determined at the end of the time step $t_{n+1}$. Using the values of $\theta$ and $\phi_{u}$ at $t_{n}$ the value of $p_{e}$ at $t_{n+1}$ is then determined. If neither the compaction nor the dilation functions $g_{c}$ and $g_{d}$ are positive then $\phi_{u}$ remains constant. On the other hand. if $g_{c}$ is positive then compaction is indicated and the value of $\phi_{\mathrm{u}}$ is decreased until $\mathrm{g}_{\mathrm{c}}$ vanishes. Similarly, if $\mathrm{g}_{\mathrm{d}}$ is positive then dilation is indicated and the value of $\phi_{\mathrm{u}}$ is increased until $g_{d}$ vanishes. Once $\phi_{\mathrm{u}}$ is determined, the estimate of $\varepsilon$ is corrected and $(9 \mathrm{~b})$ is solved iteratively to determine the value of $\theta$ at the end of the time step. Then the procedure is continued for the next time step.

\section{EXAMPLES}

The experiments of Heard et al. ${ }^{9}$ on isothermal hydrostatic quasi-static loading of Mt. Helen tuff were used to determine the material constants and functions. In particular, the function $\psi_{s}$ was chosen (0) match Hugoniot data for silicone dioxide ${ }^{10}$ with a moditied density appropriate to tuff and $\psi_{\mathrm{f}}$ was chosen to match Hugoniot data for water ${ }^{\prime \prime}$. Also. the initial porosity of the Tuff was measured to be $₫=0.38$.

The values of the material constants $a$ and $b$ in (11) were determined by matching the experimental unloading curve from 4.0 GPa and the function $\mathrm{f}(\phi)$ in (13) was determined by matching the experimental loading curve. both for dry response. Also. the value of $\kappa_{d}$ in (14) was chosen to be small in order to simulate weak response in tension.

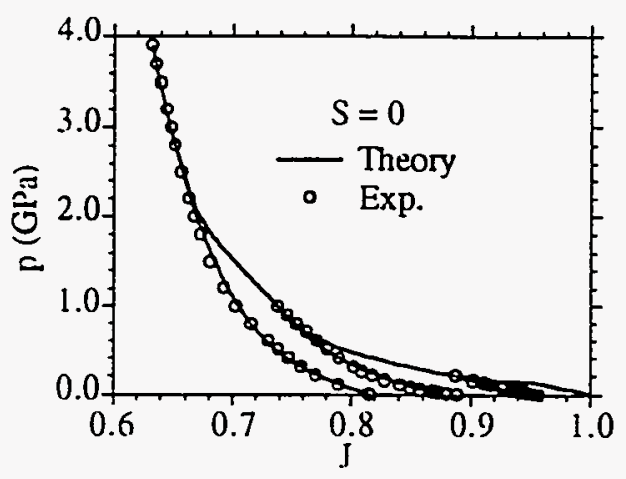

FIGURE 1. Dry response.

Figure 1 shows that the theoretical prediction of the unloading curves for dry $(S=0)$ response are very close 10 the experimental data even though only the unloading curve from 4.0 GPa was used to determine the material constants controlling the added compressibility of porosity.

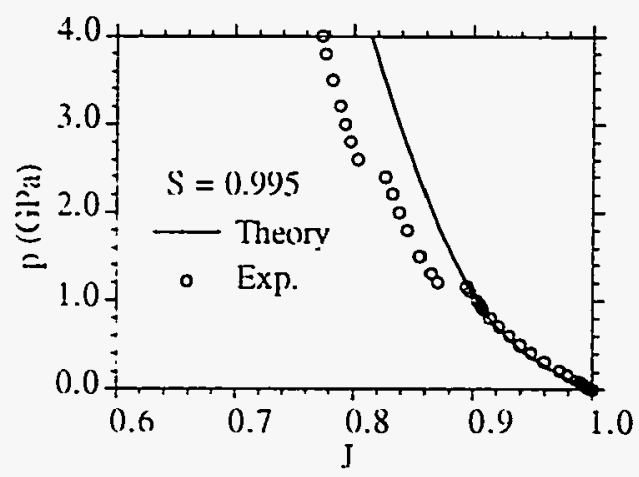

FIGURE 2. Nearly saturated response.

Figure 2 shows the predictions for near fully saturated $(S=0.995)$ response and Fig. 3 shows the predictions for partially saturated $(S=0.69)$ response. These figures show two known phase transformations of water which were not incorporated into the constitutive model. Of particular importance is the fact that even though the material constants and functions were determined by the dry response only. the theoretical predictions of the fully and partially saturated responses agree well with experimental data. 


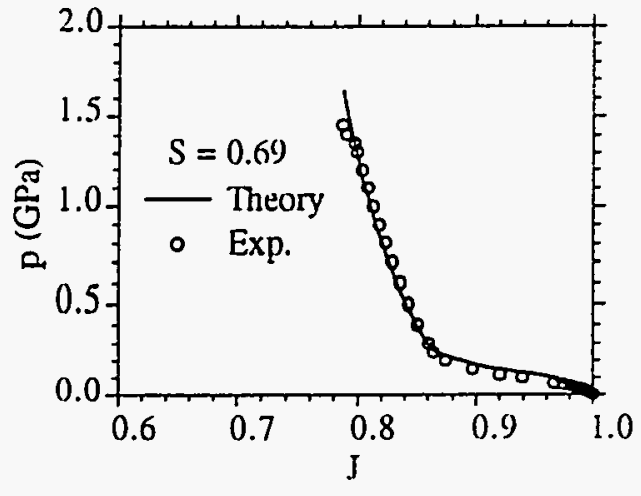

FIGURE 3. Partially saturated response.

\section{DISCUSSION AND CONCLUSIONS}

Constitutive equations have been developed to describe the thermomechanical response of a porous brittle solid whose pores may be dry or partially filled with fluid. This model also includes the added elastic compressibility of porosity that has been observed in quasi-static experiments on tuff. This softening effect of porosity has been shown ${ }^{12}$ to significantly intluence peak velocities in spherical wave propagation problems.

It is expected that the present model predicts reasonable values for the effective pressure $\mathrm{p}_{\mathrm{e}}$ for moderate values of total pressure. At high values of total pressure the predicted values of effective pressure are quite sensitive to the specific functional form proposed tor the added compressibility of porosity. However, at high values of total pressure the effect of $p_{e}$ is predicted to remain small since the solid and fluid are nearly in pressure equilibrium.

\section{ACKNOWLEDGEMENTS}

The authors would like to acknowledge helpful discussions with Dr. L. Glenn and Dr. D. Young. Part of this work was performed under the auspices of the United States Department of Energy at Lawrence Livermore National Laboratory under Contract No. W-7405-ENG-48 while M. B. Rubin was on leave from Technion, and part was supported specifically by the Geosciences Research Program of the Department of Energy Office of Energy Research within the Office of Basic Energy Sciences. Division of Engineering and Geosciences.

\section{REFERENCES}

1. Ruhin. M.B.. Elata. D.. Attia, A.V., "Modeling Added Compressihility Of Porosity And The Thermomechanical Response Of Wet Porous Rock With Application To Mt. Helen Tuff," to appear in Int. J. Solids and Structures (1995).

2. Hermann, W.. "Constitutive Equation For The Dynamic Compaction Of Ductile Porous Materials," J. Appl. Phys. 40, 2490-2499 (1969).

3. Carroll. M. M., and Holt, A. C.. "Suggested Modification of The $P-\alpha$ Model For Porous Materials," J. Appl. Phys. 43, 759-761 (1972).

4. Carroll. M. M.. and Holt, A. C.. "Static And Dynamic Pore-Collapse Relations For Ductile Porous Materials." .I. Appl. Plyss. 43, 1626-1635 (1972).

5. Carroll. M. M. "Mechanical Response Of FluidSuturated Porous Materials," in Theoretical and Applied Mechanics. (Eds. F. P. J. Rimrott and B. Tabarrok). North-Holland Pub., Amsterdam, 1980. pp. 251-262.

6. Jatger, J. C.. and Cook. N. G. W.. Fundamentals of Rock Mechanics. Halsted Press. New York, 1976. p.219

7. Green. A. E.. and Naghdi. P. M.. "On Thermodynamics And The Nature Of The Second Law." Proc. Royal Soc. Lond. A 357, 253-270 (1977).

8. Green. A. E., and Naghdi, P. M.. "The Second Law Of Thermodynamics And Cyclic Processes," ASME J. Appl. Mech. 45, 487-492 (1978).

ๆ. Heard. H. C.. Bonner. B. P.. Duha. A. G.. Shock. R. N.. and Sitephens. D. R.. "High Pressure Mechanical Properties Of Mt. Helen. Nevada, Tuff. Report No. UCID-16261, Lawrence Livermore National Lahoratory. Livermore, CA, 1973.

10. Ree. F. H.. "Equation Of State Of The Silicon Dioxide System." No. UCRL-52153, Lawrence Livermore National Laboratory. Livermore. CA. 1976.

11. Ree. F. H.. "Equation Of State Of Water." No. UCRL-52190. Lawrence Livermore National Laboratory. Livernore. CA. 1976.

12. Attia. A. V. and Rubin. M. B.. "The Effect of Dilatancy On The Inloading Behavior of $\mathrm{Mt}$. Helen Tuff." in Proceedings of The Numerical Modelin.' For Underyround Nuclear Test Monitoring Symposium, held in Durango. Colorado on March 23-25. 1993. Los Alamos National Laboratory Report No. LA-UR-93-3839. 